\title{
Osseointegrated Finger Prostheses Using a Tripod Titanium Mini-Plate
}

\author{
Oscar J. Manrique ${ }^{1}$, Pedro Ciudad ${ }^{1}$, Matthew Doscher ${ }^{2}$, Federico Lo Torto ${ }^{1}$, Ralph Liebling ${ }^{2}$, \\ Ricardo Galan ${ }^{3}$ \\ ${ }^{1}$ Department of Plastic and Reconstructive Surgery, China Medical University Hospital, Taichung, Taiwan; ${ }^{2}$ Division of Plastic and \\ Reconstructive Surgery, Albert Einstein College of Medicine, New York, NY, USA; ${ }^{3}$ Departamento De Cirugía Plástica y Reconstructiva, \\ Hospital Militar Central, Universidad Militar "Nueva Granada”, Bogotá, Colombia
}

Background Digital amputation is a common upper extremity injury and can cause significant impairment in hand function, as well as psychosocial stigma. Currently, the gold standard for the reconstruction of such injuries involves autologous reconstruction. However, when this or other autologous options are not available, prosthetic reconstruction can provide a functionally and aesthetically viable alternative. This study describes a novel technique, known as a tripod titanium mini-plate, for osseointegrated digit prostheses, and reviews the outcomes in a set of consecutive patients.

Methods A retrospective review of patients who underwent 2-stage prosthetic reconstruction of digit amputations was performed. Demographic information, occupation, mechanism of injury, number of amputated fingers, and level of amputation were reviewed. Functional and aesthetic outcomes were assessed using the quick disabilities of the arm, shoulder, and hand (Q-DASH) scale and a visual analog scale (VAS) score, respectively. In addition, complications during the postoperative period were recorded.

Results Seven patients were included in this study. Their average age was 29 years. Five patients had single-digit amputations and 2 patients had multiple-digit amputations. Functional and aesthetic outcomes were assessed using the Q-DASH score (average, 10.4) and VAS score (average, 9.1), respectively. One episode of mild cellulitis was seen at 24 months of follow-up. However, it was treated successfully with oral antibiotics. No other complications were reported.

Conclusions When autologous reconstruction is not suitable for digit reconstruction, prosthetic osseointegrated reconstruction can provide good aesthetic and functional results. However, larger series with longer-term follow-up are required in order to rule out the possibility of other complications.

Keywords Osseointegration / Prostheses / Amputation / Outcome assessment
Correspondence: Oscar J. Manrique Department of Plastic and Reconstructive Surgery, China Medical University Hospital, 5F, First Medical Building. 2, Yuh-Der Road, Taichung City 40447, Taiwan

Tel: +886-4-2205-2121

Fax: +886-4-2202-0038

E-mail: oscarj.manrique@gmail.com

This article was presented at the American Association for Hand Surgery, January 21-24, 2015, Bahamas, Paradise Island.

This article contains Supplemental Video S1.

No potential conflict of interest relevant to this article was reported.

Received: 8 Jul $2016 \bullet$ Revised: 15 Sep $2016 \bullet$ Accepted: 18 Oct 2016

pISSN: 2234-6163• elSSN: 2234-6171 • https://doi.org/10.5999/aps.2017.44.2.150 • Arch Plast Surg 2017;44:150-156

\section{INTRODUCTION}

Digital amputation is the most common type of injury of the upper extremities [1-3]. Hand and digital injuries account for $>4.8$ million visits to emergency departments in the U.S. every year [4]. Traumatic or congenital absence of the fingers can pro- 
duce major impairments in hand function, leading to the inability to perform more precise maneuvers and engage in specific tasks, as well as decreasing the power of the grip, causing social inhibition and inadequate adaptation to society [5-9].

Several reports have described reconstructive techniques for improving hand mechanics, aesthetics, and functionality after congenital or traumatic amputation of the fingers [10-12]. With the advance of microsurgical techniques in reconstructive surgery, many centers offer autologous reconstruction of the hand and replantation [13-16]. However, when microsurgical reconstruction fails or when replantation is not an option due to the mechanism of injury, techniques such as finger pollicization or toe-to-hand transfer can also offer a good reconstructive alternative $[13,17,18]$. In some circumstances, when these options are not feasible and patients still desire to improve their finger functionality and aesthetics, other reconstructive procedures may be considered.

The use of bone-anchored implants with the anchoring of silicone prostheses represents an alternative technique $[6,7,19]$. Implant techniques and concepts of osseous integration have been used for more than 30 years in oral surgery to correct congenital or acquired craniofacial deformities [20]. However, when this technique has been applied in hand reconstruction, most of the reports in the literature have described a low number of patients and high rates of infection, extrusion of the prosthesis, and osseoabsorption of the phalangeal stump $[5,21,22]$.

The aim of this study was to describe our experience using a novel technique, known as the tripod titanium mini-plate, as a potential alternative option for finger reconstruction when autologous tissue is not suitable.

\section{METHODS}

This is a retrospective review of a single surgeon's experience (RG) with patients who had traumatic amputation(s) of the finger(s) and then underwent reconstruction using this technique. Demographic information, occupation, mechanism of injury, number of amputated fingers, and level of amputation were recorded. In order to assess functional outcomes, the quick disability of the arm, shoulder, and hand (Q-DASH) score was obtained 12 months after surgery. In addition, a visual analog scale (VAS) score was used for a subjective assessment of the appearance of the prostheses, length, color match, likeness, and frequency of prosthesis use. The VAS scores were obtained by showing the patient a $10-\mathrm{cm}$ horizontal line with 10 (full function, no complaints) marked on the far right and 0 (no function, strong complaints) marked on the far left. The patient was asked to mark a point along the line indicating the level of function,

\section{Fig. 1. Mini-plate design}

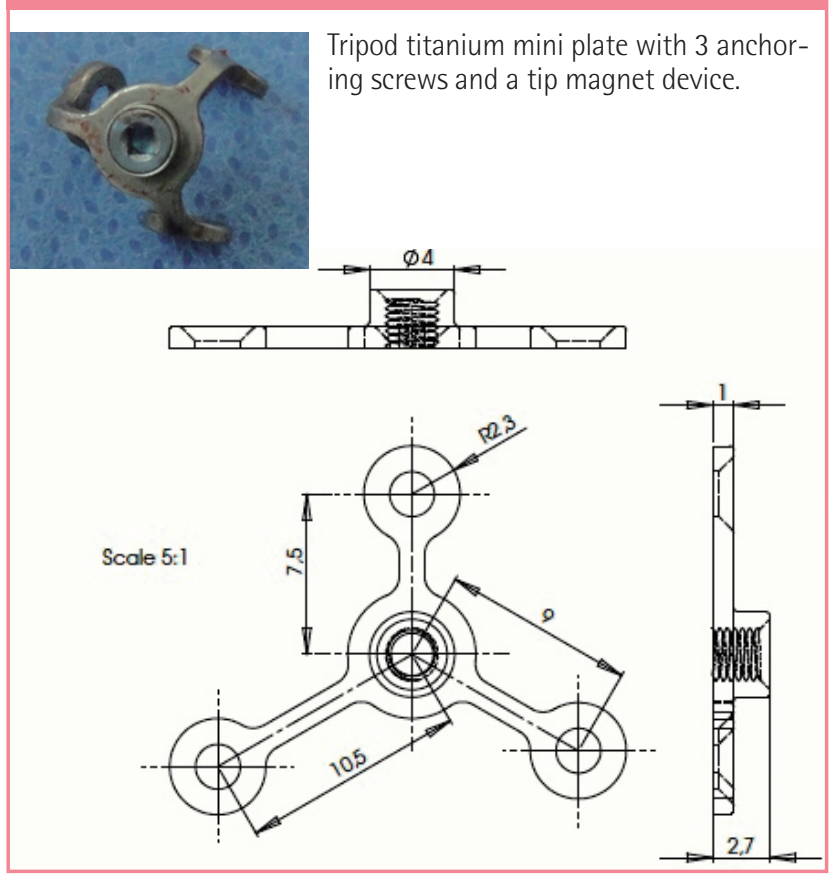

size, length, and so forth. This score was measured and compared among patients. Statistical analysis using a descriptive method was performed. Over 24 months of postoperative follow-up, all complications were recorded and analyzed.

\section{Technique}

All patients underwent surgical reconstruction under regional anesthesia. This is a 2- stage procedure in which the distal phalangeal stump is revised and a tripod titanium mini-plate (Epiplating System, Medicon, Tuttligen, Germany) Medicon, Epiplating System, Germany) is anchored and secured in 3 axes with $1.5 \mathrm{~mm}$ mini-plates and screws (Fig. 1). The principle of this technique is based on a mini-plate with screws that are anchored at an equidistant point from each other on 3 axes of $180^{\circ}$ each. This allows a more stable implant with regard to lateral torque movements and also prevents loosening of the prosthesis during insertion and removal of the external silicone finger, which has been reported with other techniques, such as the intramedullary technique. In addition, since this technique does not involve the placement of any intramedullary components, it decreases the amount of stress over the phalanx, thus preventing fractures or weakening of the distal phalangeal stump.

After anchoring, the mini-plates and screws are covered with adjacent soft tissue flaps, leaving just a small magnetic tip outside of the phalangeal stump (Fig. 2). Intraoperative X-rays were performed to confirm adequate implant placement. Immediately after surgery, the hand is maintained in elevation until the patient is discharged home. A dorsal hood splint is placed for the 


\section{Fig. 2. Mini-plate placement}

(A) Adjustment of the titanium tripod to the distal phalangeal stump. (B) Soft tissue closure of the phalangeal stump with exposure of the anchoring magnet.
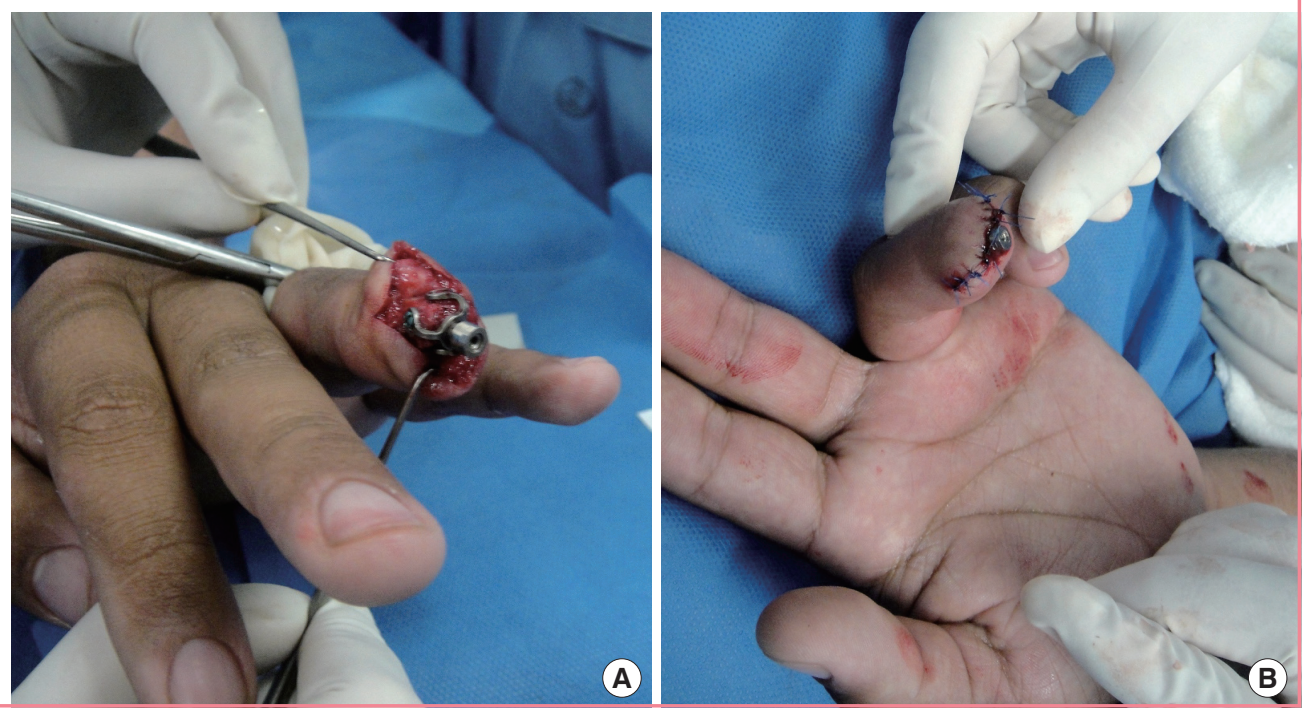

Fig. 3. Postoperative hand X-ray

(A) Anteroposterior and (B) lateral hand X-rays 6 months after surgery show no lucency around the plates and screws, which is associated with adequate osseointegration of the prostheses at the distal phalangeal stump.
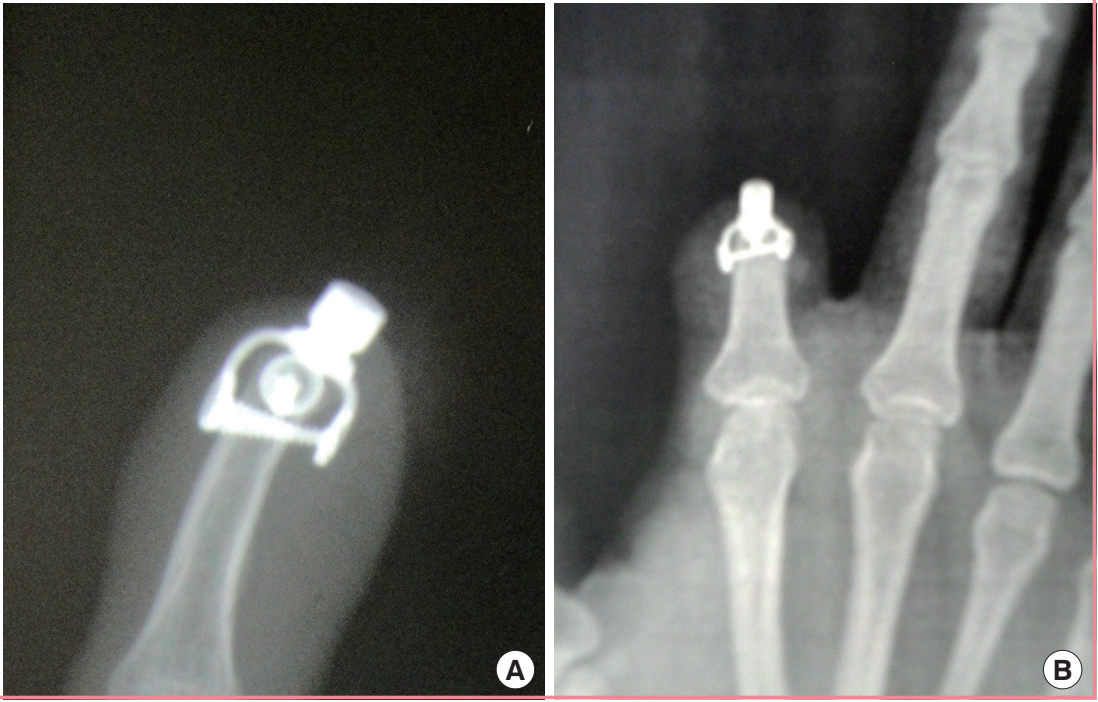

first 2 months, in order to prevent direct contact of the implant with other objects and to reduce the risk of catching the abutments and loosening the implants during the time of osseointegration. Four months after surgery, a hand X-ray was performed in order to confirm osseointegration of the prosthesis with the distal stump and to rule out any other potential complications in the postoperative period (Fig. 3). The patients underwent a second reconstructive stage, which consists of the placement of pre-fabricated magnetic finger silicone prosthesis to the tip of the tripod mini-plate 4 months after the first intervention. These finger prostheses were made based on the contralateral hand to match the color, length, and width of the missing digit(s) (Finger Prosthesis, Arte Protesis, Bogota, Cundinamarca, Colombia).

\section{RESULTS}

A total of 7 patients were included in our study ( 5 males and 2 females). Ten digit reconstructions were performed. The patients' average age was 29 years (range, 20-40 years). Avulsion was the most common mechanism of injury. Five patients had a single-digit amputation, with the index finger the most common (Patient 3; Fig. 4). Two patients had multiple amputated digits (digits 2, 3, and 4 and digits 2 and 3 ) respectively (Patient 1; Fig. 5). Regarding the level of amputation, 4 patients presented with amputation at the proximal phalanx and 3 patients with amputation at the middle phalanx. The average follow-up was 24.4 months (range, 14-40 months) (Table 1). Four months after the first stage, a hand $\mathrm{X}$-ray was performed in order to confirm 


\section{Fig. 4. Insertion and color match of prostheses}

(A) Postoperative picture of Patient 1 with the right index finger prostheses prior to insertion with exposure of magnetic tip. (B) Fitting of the right index finger prostheses to demonstrate color and length match. (C) Patient demonstrating fitting of pen into the right hand (writing) as a functional outcome.
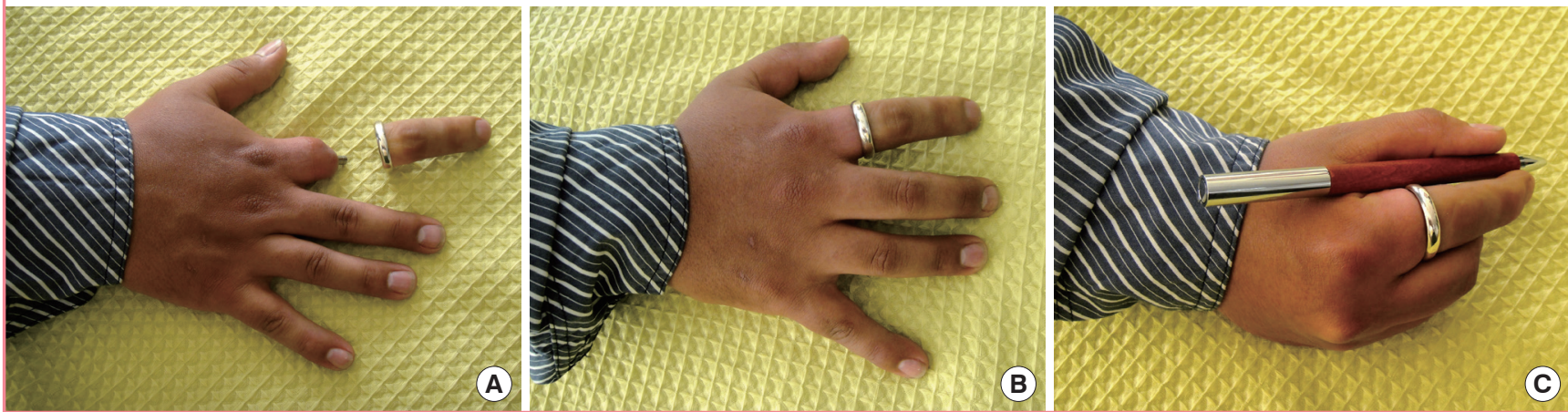

Fig. 5. Patient with amputation of multiple digits

Patient 2. (A) Multiple digit amputation (digits 2, 3, and 4) of the right hand. (B) Three-dimensional reconstruction of the missing digits. (C) Dorsal and (D) volar aspects of the right hand after the prostheses were placed.
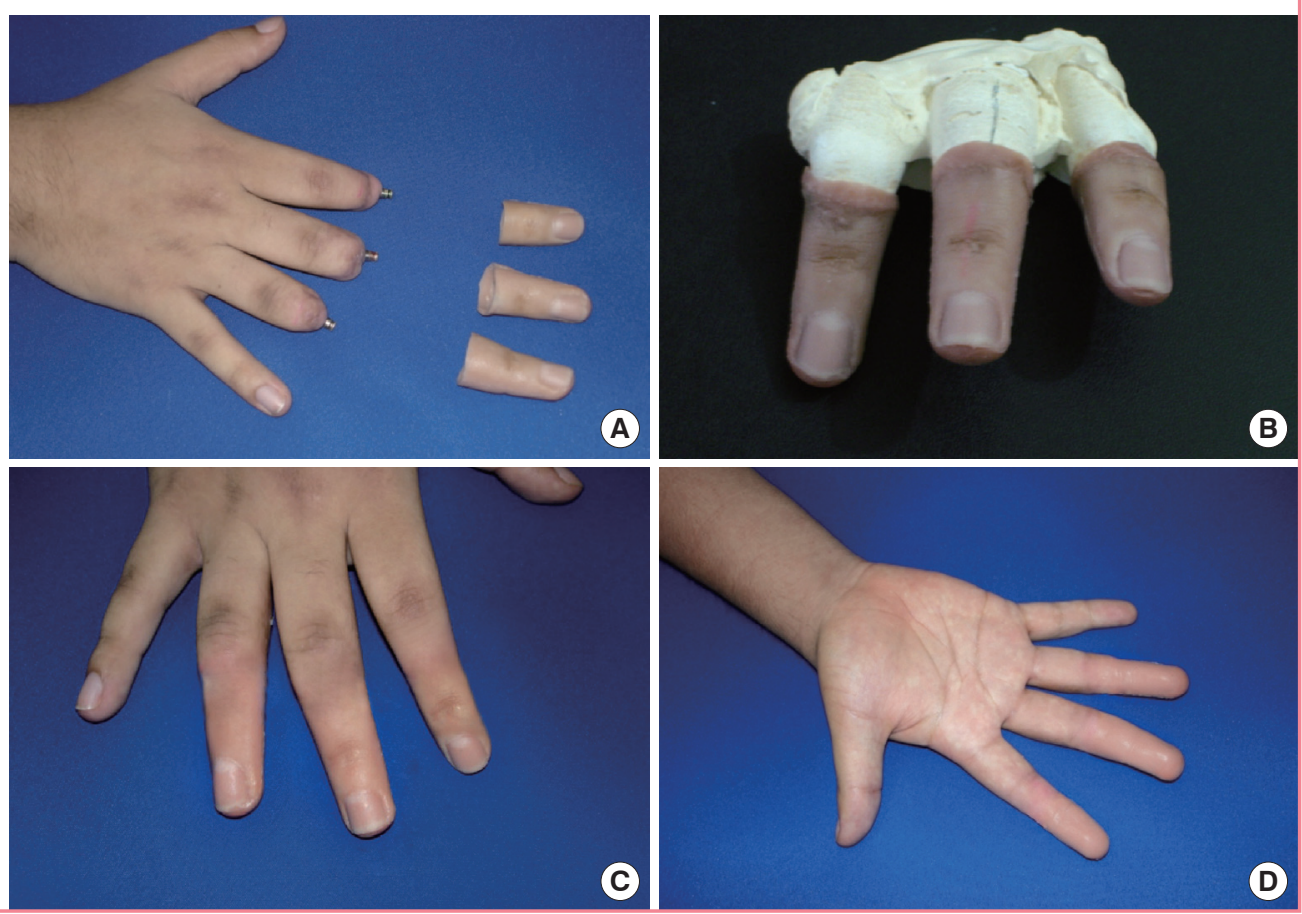

osseointegration of the prosthesis to the distal phalangeal stump. No signs of bone resorption, infection, extrusion of the prosthesis, or lucency between the plate and phalanx were observed (Fig. 3). In addition, no prosthesis failure was observed in any of our patients. Regarding hand functionality, patients were asked to return to our clinic 12 months after surgery to assess functional outcomes based on the Q-DASH score (Table 2). An average score of 10.41 (range, 6.8-11.4) was reported for all 11 items of the Q-DASH score. A video of one of our patients several months after reconstruction is presented in Supplemental Video S1. Regarding aesthetic outcomes, all of our patients $(n=7)$ were very satisfied with the aesthetic results and reported a high frequency of prosthesis use based on the VAS (average, 9.1) (Table 3). Regarding complications, 1 patient did not follow postoperative instructions and was lost to follow-up several months after the initial intervention. He presented with a mild episode of cellulitis 3 months after the initial operation; however, it resolved with a course of oral antibiotics (patient 7). No major complications were seen at the 2-year follow-up (Table 1).

\section{DISCUSSION}

The loss of any digit has functional, aesthetic, and psychological sequelae $[2,11,15]$. In circumstances where digital reconstruc- 
Table 1. Demographics and background

\begin{tabular}{|c|c|c|c|c|c|c|c|c|c|c|}
\hline Patient & Sex & Age (yr) & Hand & $\begin{array}{l}\text { Amputated } \\
\text { finger }\end{array}$ & Level & Occupation & Mechanism & $\begin{array}{l}\text { Follow-up } \\
\text { (mo) }\end{array}$ & Complications & $\begin{array}{l}\text { Prosthetic } \\
\text { failure }\end{array}$ \\
\hline 1 & Male & 20 & Right & $2,3,4$ & $\mathrm{MP}$ & Student & Sharp & 40 & No & No \\
\hline 2 & Male & 34 & Right & 4 & MP & Military & Crush & 32 & No & No \\
\hline 3 & Male & 26 & Right & 2 & PP & Military & Avulsion & 25 & No & No \\
\hline 4 & Male & 22 & Left & 2 & PP & Student & Crush & 22 & No & No \\
\hline 5 & Female & 28 & Right & 2.3 & PP & Secretary & Sharp & 20 & No & No \\
\hline 6 & Male & 40 & Left & 4 & MP & Military & Avulsion & 18 & No & No \\
\hline 7 & Female & 33 & Right & 2 & PP & Secretary & Avulsion & 14 & Cellulitis & No \\
\hline
\end{tabular}

Table 2. Quick disabilities of the arm, shoulder, and hand (Q-DASH) scores

\begin{tabular}{|c|c|c|c|c|c|c|c|c|c|c|c|c|}
\hline Patient & Open jar & $\begin{array}{c}\text { Heavy } \\
\text { household }\end{array}$ & $\begin{array}{c}\text { Carrying } \\
\text { shopping } \\
\text { bag }\end{array}$ & $\begin{array}{c}\text { Wash your } \\
\text { back }\end{array}$ & $\begin{array}{l}\text { Cut your } \\
\text { food }\end{array}$ & $\begin{array}{l}\text { Recreational } \\
\text { activities }\end{array}$ & $\begin{array}{c}\text { Social } \\
\text { activities }\end{array}$ & $\begin{array}{c}\text { Work/ } \\
\text { Regular } \\
\text { activities }\end{array}$ & Pain & Tingling & Sleep & $\begin{array}{l}\text { Q-DASH } \\
\text { score }\end{array}$ \\
\hline 1 & 2 & 2 & 1 & 1 & 2 & 1 & 1 & 1 & 2 & 1 & 1 & 9,1 \\
\hline 2 & 1 & 1 & 1 & 2 & 2 & 2 & 2 & 1 & 1 & 1 & 2 & 11,4 \\
\hline 3 & 1 & 1 & 2 & 1 & 1 & 2 & 1 & 1 & 2 & 1 & 1 & 6,8 \\
\hline 4 & 2 & 2 & 1 & 1 & 1 & 2 & 1 & 1 & 1 & 2 & 2 & 11,4 \\
\hline 5 & 1 & 1 & 2 & 2 & 1 & 2 & 2 & 1 & 1 & 1 & 2 & 11,4 \\
\hline 6 & 2 & 2 & 1 & 2 & 1 & 1 & 2 & 2 & 1 & 1 & 1 & 11,4 \\
\hline 7 & 3 & 2 & 2 & 2 & 2 & 2 & 1 & 2 & 2 & 2 & 1 & 11,4 \\
\hline
\end{tabular}

\section{Table 3. Visual analog scale (VAS) scores}

\begin{tabular}{lccccccc}
\hline Patient & Size & Length & Flexion & Color match & Likeness & Overall appearance & Use of prosthesis \\
\hline 1 & 9 & 9 & 9 & 10 & 9 & 9 & 9 \\
2 & 8 & 9 & 8 & 9 & 9 & 10 & 9 \\
3 & 10 & 8 & 8 & 10 & 10 & 10 & 9 \\
4 & 10 & 9 & 9 & 10 & 9 & 10 & 10 \\
5 & 9 & 9 & 9 & 9 & 9 & 10 \\
6 & 9 & 8 & 8 & 9 & 9 \\
7 & 9 & 9 &
\end{tabular}

tion is anticipated, autologous reconstruction should be considered the gold standard $[2,3,12]$. However, this option is not always available. The concept of osseointegration has been applied in craniofacial reconstruction for more than 30 years [20]. However, very few studies using prosthetic implants have been reported for hand reconstruction. Osseointegration is defined as direct attachment of an implant to the bony stump by formation of the bony tissue around the implant without the growth of fibrous tissue at the bone-implant interface [9,21-23].

This novel technique allows reconstruction of the missing digit(s) when autologous tissue is not available or when the patient desires to undergo a less complicated surgical intervention. Other traditional techniques such as the Branemark dental-type implant have been described [24]. However, the total experience with osseointegrated prostheses in hand surgery is very limited [7,21,25]. Lundborg et al. [25] described 3 patients with osseointegrated thumb prostheses over a maximum of 3 years of follow-up. He concluded that these patients achieved reasonable grip function and strength compared to the uninjured hand and that it was a better tool for fine manipulative tasks. Manurangsee et al. [7] reported 3 patients with osseointegrated prostheses placed on the proximal phalanx and middle fingers. The pulp and lateral pinch strengths were approximately $50 \%$ of those observed for the contralateral hand, and grip strength was $29 \%-43 \%$ of the contralateral hand. In addition, these patients achieved high scores on the Jebsen Hand Func- 
tion Test [7]. Sierakowski et al. [21] reported 3 patients, 1 of whom was followed for 13 years. Their technique was used in a range of digits, including the thumb. They concluded that successful results were achieved in highly motivated and cooperative patients as measured objectively by the Jebsen Hand Function Test. In addition, this technique can be useful for thumb reconstruction.

In our experience, this novel technique is less invasive than traditional techniques. This technique does not create a medullary tunnel in order to insert the implant within the distal phalanx, reducing the chance of phalangeal fracture or misplacement of the prostheses. The main intention with any finger prosthetic technique, including this one, is not to improve the strength of the hand, but to improve the aesthetic appearance. However, due to the high number of complications (e.g., infection and extrusion) reported in the literature with other prosthetic techniques, patient selection is paramount in order to minimize complications [19-21,23]. We believe that this technique can be applied in selected group of patients with conditions such as thumb amputation when no autologous tissue is available or if multiple-digit amputations occur, as was the case for 2 of our patients. Regarding functionality, the Q-DASH score showed that the majority of our patients had excellent functional outcomes and were able to tolerate the prostheses with no pain. This is very reassuring, as it gives us some sense of how these patients can reintegrate into their normal daily activities. Regarding aesthetic outcomes, the VAS score showed that most of the patients were happy with the length, color, and size of the implant. In addition, they were using the prostheses most of the time. We believe that the aesthetic results are as important as the functional results. A combination of good functional and aesthetic outcomes will keep patients motivated, reduce their social inhibition, assist them in adaptation to society, and help them cope with their daily routines.

However, this technique has some limitations. Patients with diabetes, smokers, or patients who perform major heavy manual labor are not candidates due to the possible risk of wound complications. These patients require a high degree of motivation and awareness, since they require a 2 -stage surgical intervention and close follow-up, especially during the first several weeks after surgery and during occupational therapy, in order to minimize complications and optimize final outcomes. As occurred in one of our patients, lack of follow-up, possible lack of self-motivation and improper hygiene of the prosthesis can lead to a poor outcome. As seen in other series, infection still remains a major cause of concern with osseointegrated prostheses [20,23]. In the postoperative period, meticulous hygiene of the prostheses is required in order to prevent infection of the stump because the distal magnetic tip is exposed at all times. In the ideal patient, the long-term benefits of good cosmesis, prosthesis stability, and functionality should always be weighed against the small but real risk of infection.

However, the main limitation of our study is the short-term follow-up (24 months). Even though this is a novel technique never reported before that has some promising outcomes, it is premature to draw final conclusions regarding the possibility of other complications over a short period of time, and long term follow-up is required to rule out any unexpected outcomes.

In addition, candidates for surgical reconstruction using this technique require a digital stump of at least $1.5 \mathrm{~cm}$ in length to secure the titanium tripod over the distal phalangeal stump and to prevent lateral tilting or instability of the prosthesis.

Autologous reconstruction still remains the gold standard for the reconstruction of digits of the hand. However, when autologous tissue is not an option or advanced microsurgical techniques are not available, osseointegrated digital prostheses can be considered in appropriate patients when aesthetic and functional improvements are desired.

\section{REFERENCES}

1. Leigh JP, Markowitz SB, Fahs M, et al. Occupational injury and illness in the United States: estimates of costs, morbidity, and mortality. Arch Intern Med 1997;157:1557-68.

2. Chung KC, Shauver MJ. Table saw injuries: epidemiology and a proposal for preventive measures. Plast Reconstr Surg 2013;132:777e-783e.

3. Sears ED, Chung KC. Replantation of finger avulsion injuries: a systematic review of survival and functional outcomes. J Hand Surg Am 2011;36:686-94.

4. Conn JM, Annest JL, Ryan GW, et al. Non-work-related finger amputations in the United States, 2001-2002. Ann Emerg Med 2005;45:630-5.

5. Goodacre CJ, Bernal G, Rungcharassaeng K, et al. Clinical complications with implants and implant prostheses. J Prosthet Dent 2003;90:121-32.

6. Aydin C, Karakoca S, Yilmaz H. Implant-retained digital prostheses with custom-designed attachments: a clinical report.J Prosthet Dent 2007;97:191-5.

7. Manurangsee $P$, Isariyawut $C$, Chatuthong V, et al. Osseointegrated finger prosthesis: an alternative method for finger reconstruction. J Hand Surg Am 2000;25:86-92.

8. Shanmuganathan N, Maheswari MU, Anandkumar V, et al. Aesthetic finger prosthesis. J Indian Prosthodont Soc 2011; 11:232-7.

9. Aydin C, Karakoca S, Yilmaz H, et al. The use of dental im- 
plants to retain thumb prostheses: a short-term evaluation of 2 cases. Int J Prosthodont 2008;21:138-40.

10. Rampazzo A, Kutz JE, Kaufman C, et al. A cadaver study of the feasibility of multidigit allotransplantation for reconstruction of the metacarpal hand. Plast Reconstr Surg 2015; 136:531-40.

11. Yuan F, McGlinn EP, Giladi AM, et al. A systematic review of outcomes after revision amputation for treatment of traumatic finger amputation. Plast Reconstr Surg 2015;136:99113.

12. Wilhelmi BJ, Lee WP, Pagenstert GI, et al. Replantation in the mutilated hand. Hand Clin 2003; 19:89-120.

13. Buncke GM, Buncke HJ, Lee CK. Great toe-to-thumb microvascular transplantation after traumatic amputation. Hand Clin 2007;23:105-15.

14. Wang H. Secondary surgery after digit replantation: its incidence and sequence. Microsurgery 2002;22:57-61.

15. Bueno RA Jr, Battiston B, Ciclamini D, et al. Replantation: current concepts and outcomes. Clin Plast Surg 2014;41: 385-95.

16. Jazayeri L, Klausner JQ Chang J. Distal digital replantation. Plast Reconstr Surg 2013;132:1207-17.

17. Pet MA, Ko JH, Vedder NB. Reconstruction of the traumatized thumb. Plast Reconstr Surg 2014;134:1235-45.
18. Taghinia AH, Littler JW, Upton J. Refinements in pollicization: a 30-year experience. Plast Reconstr Surg 2012;130: 423e-433e.

19. Cervelli V, Bottini DJ, Arpino A, et al. Bone-anchored implant in cosmetic finger reconstruction. Ann Chir Plast Esthet 2008;53:365-7.

20. Branemark PI. Osseointegration and its experimental background. J Prosthet Dent 1983;50:399-410.

21. Sierakowski A, Watts C, Thomas K, et al. Long-term outcomes of osseointegrated digital prostheses for proximal amputations. J Hand Surg Eur Vol 2011;36:116-25.

22. Doppen P, Solomons M, Kritzinger S. Osseointegrated finger prostheses. J Hand Surg Eur Vol 2009;34:29-34.

23. Jonsson S, Caine-Winterberger K, Branemark R. Osseointegration amputation prostheses on the upper limbs: methods, prosthetics and rehabilitation. Prosthet Orthot Int 2011;35:190-200.

24. Branemark PI, Adell R, Breine U, et al. Intra-osseous anchorage of dental prostheses: I. Experimental studies. Scand J Plast Reconstr Surg 1969;3:81-100.

25. Lundborg G, Branemark PI, Rosen B. Osseointegrated thumb prostheses: a concept for fixation of digit prosthetic devices. J Hand Surg Am 1996;21:216-21.

Supplemental Video S1. A video of one of our patients several months after reconstruction.

Supplemental data can be found at: http://e-aps.org/src/sm/aps-44-150-s001.mov 